International Journal of Biomathematics

Vol. 9, No. 6 (2016) 1699001 (8 pages)

(C) World Scientific Publishing Company

DOI: 10.1142/S1793524516990011

\title{
Author index (Volume 9)
}

Abbasi, F. M., Hayat, T. \& Alsaedi, A., Transport of $\mathrm{Cu}-\mathrm{H}_{2} \mathrm{O}$ nanofluid through a channel with wavy walls under velocity slip and connective boundary conditions

Adak, D., see Bairagi, $\mathrm{N}$.

Adhikary, P. R., see Gurung, D. B.

Aghdam, R., Alijanpour, M., Azadi, M.,

Ebrahimi, A.

Eslahchi, C. \& Rezvan, A., Inferring gene regulatory networks by PCA-CMI using Hill climbing algorithm based on MIT score and SORDER method

Agnihotri, K., see Sharma, A. K.

Akbar, N. S., Metallic nanoparticles analysis for the blood flow in tapered stenosed arteries: Application in nanomedicines

Ali, A., see Mohyud-Din, S. T.

Alijanpour, M., see

Aghdam, R.

Alsaedi, A., see Abbasi, F. M.

Alsaedi, A., see Hayat, $\mathrm{T}$.

Alsaedi, A., see Hussain, Q.

Alsaedi, A., see Javed, M.
3 (2016) 1650040

2 (2016) 1650022

6 (2016) 1650096

1 (2016) 1650006

6 (2016) 1650086

1 (2016) 1650002

5 (2016) 1650070

3 (2016) 1650040

2 (2016) 1650022

1 (2016) 1650012

2 (2016) 1650029

1 (2016) 1650010
AlShamrani, N. H., see Ełaiw, A. M.

4 (2016) 1650060

Andrade, H., Nieto, J. J. \& Torres, A., The number of alignments between two DNA sequences

4 (2016) 1650053

Asghar, S., see Hussain, Q.

2 (2016) 1650029

1 (2016) 1650012

Ayub, M., see Hayat, T

Azadi, M., see Aghdam, $\mathrm{R}$.

3 (2016) 1650040

Badr, M. S., see El-Sharkasy, M. M.

Bahi, J. M., Guyeux, C. \& Perasso, A., Chaos in DNA evolution

4 (2016) 1650054

5 (2016) 1650076

Bairagi, N. \& Adak, D., Role of precautionary measures in $\mathrm{HIV}$ epidemics: $A$ mathematical assessment

6 (2016) 1650096

Banerjee, S., Keval, R. \& Gakkhar, S., Global dynamics of hepatitis $C$ viral infection with logistic proliferation

4 (2016) 1650056 1 (2016) 1650012

Batool, N., see Hayat, T.

Bekir, A., see Jabbari, A.

6 (2016) 1650090

Bin-Mohsin, B., see Iqbal, M. A.

5 (2016) 1650071

Bin-Mohsin, B., see Mohyud-Din, S. T.

Cai, S., see Jiao, J.

Chakravarty, S., see Guin, L. N.

Chatterjee, A. N., see Roy, P. K.

5 (2016) 1650070

5 (2016) 1650084

6 (2016) 1650085

1 (2016) 1650005

5 (2016) 1650072

Chen, M., see Pei, Y.

Cimpoiasu, R., Nerve pulse propagation in 
biological membranes:

Solitons and other invariant solutions

Das, P., see Ghosh, P.

Davvaz, B. \& Hassani Sadrabadi, E., An application of intuitionistic fuzzy sets in medicine

De, A., Maity, K. \& Maiti, M., An integrated project of fish and broiler: SIS model with optimal harvesting

Devi, R., see Kannan, S. R.

Dey, B. \& Raja Sekhar, G. P., A theoretical study on the elastic deformation of cellular phase and creation of necrosis due to the convection reaction process inside a spherical tumor

Din, Q., Qualitative behavior of a discrete SIR epidemic model

Ding, Q., see Zhu, H.

Ding, X., see Liao, C.

Ebrahimi, A., see Aghdam, R.

Ekanayake, A. J., Stochastic SIS metapopulation models for the spread of disease among species in a fragmented landscape

Ełaiw, A. M. \&

AlShamrani, N. H., Global stability of a delayed virus dynamics model with multistaged infected progression and humoral immunity

El-Sharkasy, M. M. \& Badr, M. S., Topological spaces via phenotype-genotype spaces

El-Sharkasy, M. M. \& Shokry, M., Separation
5 (2016) 1650075

5 (2016) 1650073

3 (2016) 1650037

6 (2016) 1650088

2 (2016) 1650018

6 (2016) 1650095

6 (2016) 1650092

5 (2016) 1650079

4 (2016) 1650049

3 (2016) 1650040

4 (2016) 1650055

4 (2016) 1650060

4 (2016) 1650054 axioms under crossover operator and its generalized

4 (2016) 1650059

Elsayed, E. M., see Jana, D.

1 (2016) 1650004

Eslahchi, C., see Aghdam, R.

Fallahchai, M. M., see Mohammadi, F.

Fan, L., see Liu, C. Fu, Q., see Wei, F. Gakkhar, S., see Banerjee, S.

Gao, J., see Li, H.

Ghosh, P., Das, P. \& Mukherjee, D., Chaos to order: Effect of random predation in a Holling type IV tri-trophic food chain system with closure terms

5 (2016) 1650073

Gokul, K. C., see Gurung, D. B.

Guin, L. N., Mondal, B. \& Chakravarty, S., Existence of spatiotemporal patterns in the reactiondiffusion predator-prey model incorporating prey refuge

3 (2016) 1650040

3 (2016) 1650048

2 (2016) 1650017

4 (2016) 1650058

4 (2016) 1650056

4 (2016) 1650051

1 (2016) 1650006

6 (2016) 1650085

1 (2016) 1650015

Gurung, D. B., Gokul, K. C. \& Adhikary, P. R., Mathematical model of thermal effects of blinking in human eye

1 (2016) 1650006

Guyeux, C., see Bahi, J. M.

5 (2016) 1650076

Hasan, A. A., Electrogravitational stability of streaming compound jets

2 (2016) 1650032

Hashemi, S. A., see Mohammadi, F.

Hassani Sadrabadi, E., see Davvaz, B.

Hayat, T., Batool, N., Yasmin, H., Alsaedi, A. \& Ayub, M., Peristaltic flow of Williamson fluid in a convected walls
3 (2016) 1650048

3 (2016) 1650037 
channel with Soret and Dufour effects

1 (2016) 1650012

Hayat, T., see Abbasi, F. M.

Hayat, T., see Hussain, Q.

Hayat, T., see Javed, M. He, Z.-R., Xie, Q.-J. \&

Wang, H.-T., Stability analysis for a sizestructured model of species in a space-

limited habitat

Hong, T. P., see Kannan, S. R.

Huang, S., Dynamic analysis of an SEIRS model with nonlinear infectivity on complex networks

Hussain, F., see Khanday, M. A.

Hussain, Q., Asghar, S., Hayat, T. \& Alsaedi, A., Peristaltic transport of hydromagnetic Jeffrey fluid with temperature-dependent viscosity and thermal conductivity

Iqbal, M. A.,

Mohyud-Din, S. T. \&

Bin-Mohsin, B., A

study of nonlinear

biochemical reaction model

Iqbal, S., see Sarwar, S.

Islam, S., see Khan, M. A.

Jabbari, A., Kheiri, H., Jodayree Akbarfam, A. \& Bekir, A., Dynamical analysis of the avian-human influenza epidemic model using multistage analytical method

Jana, D. \& Elsayed, E. M., Interplay between strong Allee effect, harvesting and hydra effect of a single population discretetime system
2 (2016) 1650022

2 (2016) 1650029

1 (2016) 1650010

6 (2016) 1650093

2 (2016) 1650018

1 (2016) 1650009

5 (2016) 1650066

2 (2016) 1650029

5 (2016) 1650071

6 (2016) 1650081

5 (2016) 1650068

6 (2016) 1650090

1 (2016) 1650004
Javed, M., Hayat, T. \&

Alsaedi, A., $M H D$

peristaltic flow in an

inclined channel with

heat and mass

transfer

Jeon, W. \& Lee, S.-H., Stochastic rules for predator and prey hunting and escape behavior in a lattice-based model

1 (2016) 1650010

6 (2016) 1650089

Ji, X., Yuan, S. \& Zhu, H., Analysis of a stochastic model for algal bloom with nutrient recycling Ji, Z., see Wang, Z. Jiang, D., see Lin, Y. Jiang, D., see Zhao, Y. Jiang, W., see Song, H. Jiang, Y. \& Li, C., Exponential stability of memristor-based synchronous switching neural networks with time delays

1 (2016) 1650016

Jiao, J., Cai, S., Zhang, Y. \& Li, L., Dynamics of a stage-structured single population system with winter hibernation and impulsive effect in polluted environment

Jodayree Akbarfam, A., see Jabbari, A.

Kamalanand, K. \& Mannar Jawahar, P., Comparison of particle swarm and bacterial foraging optimization algorithms for therapy planning in $H I V / A I D S$ patients

6 (2016) 1650083

2 (2016) 1650019

3 (2016) 1650039

3 (2016) 1650042

3 (2016) 1650046

5 (2016) 1650084

6 (2016) 1650090

2 (2016) 1650024

Kamboj, D. \& Sharma, M. D., Effects of combined drug therapy on HIV-1 infection dynamics

5 (2016) 1650065

Kannan, S. R., Devi, R., Ramathilagam, S., Hong, T. P. \&

Ravikumar, A., Effective kernel FCM: 
Finding appropriate structure in cancer database

Keval, R., see Banerjee, $\mathrm{S}$.

Khan, A. Q. \& Qureshi, M. N., Stability analysis of a discrete biological model

Khan, M. A., Khan, Y., Khan, S. \& Islam, S., Global stability and vaccination of an SEIVR epidemic model with saturated incidence rate

Khan, S., see Khan, M. A.

Khan, Y., see Khan, M. A.

Khanday, M. A. \& Hussain, F., Thermal stability of biological tissues and their behavior in cold conditions: $A$ mathematical model

Kheiri, H., see Jabbari, A.

Kheiri, H., see Mojaver, A.

Kittisuwan, P., Medical image denoising using simple form of MMSE estimation in PoissonGaussian noise model

Lakshminarayana, P., see Vajravelu, K.

Lee, S.-H., see Jeon, W.

Li, C., see Jiang, Y.

Li, C., see Pei, Y.

Li, C., see Tan, J.

Li, H. \& Gao, J., Qualitative analysis of a parabolic-elliptic attraction-repulsion chemotaxis model with logistic source

Li, H. \& She, Z., Dynamics of a non-autonomous density-dependent predator-prey model with BeddingtonDeAngelis type
2 (2016) 1650018

4 (2016) 1650056

2 (2016) 1650021

5 (2016) 1650068

5 (2016) 1650068

5 (2016) 1650068

5 (2016) 1650066

6 (2016) 1650090

3 (2016) 1650038

2 (2016) 1650020

2 (2016) 1650023

6 (2016) 1650089

1 (2016) 1650016

5 (2016) 1650072

3 (2016) 1650041

4 (2016) 1650051

4 (2016) 1650050
Li, J. \& Li, S., Multiscale models of compact bone

3 (2016) 1650047

Li, J.-H., Wang, F., Li, J.-W., Zou, R.-B. \& Liao, G.-P., Multifractal methods for rapeseed nitrogen nutrition qualitative diagnosis modeling

Li, J.-W., see Li, J.-H.

Li, L., see Jiao, J.

Li, M., The spreading fronts in a mutualistic model with delay

Li, S., see Li, J.

Li, X., see Yang, J.

Li, X.-Z., see Roy, P. K.

Li, Y., Zhang, L. \& Guo, G., The asymptotic stability for an SIQS epidemic model with diffusion

1 (2016) 1650015

4 (2016) 1650049

5 (2016) 1650072

Liang, X., see Pei, Y.

Liao, C., Ding, X. \&

Liang, J.,

Combinations of

nonstandard finite

difference schemes and

composition methods

with complex time

steps for population models

4 (2016) 1650064

4 (2016) 1650064

5 (2016) 1650084

6 (2016) 1650080

3 (2016) 1650047

3 (2016) 1650033

1 (2016) 1650005

Liao, G.-P., see Li, J.-H.

Lin, Y. \& Jiang, D. Long-time behavior of a stochastic predator-prey model with modified Leslie-Gower and Holling-type II schemes

3 (2016) 1650039

Liu, C. \& Fan, L., Evolutionary algorithm based on dynamical structure of membrane systems in uncertain environments

Liu, J., see Yu, M.

Liu, M. \& Wang, K., Survival analysis of a stochastic singlespecies population
4 (2016) 1650049

4 (2016) 1650064 
model with jumps in a polluted environment Liu, S., see Song, H. Liu, Z., see Tian, B. Lv, W., Parameter identification for volumetric heat capacity and thermal conductivity in a quasi-linear thermodynamic system of sea ice

Lv, Y., see Pei, Y. Mahapatra, G. S. \& Santra, P., Preypredator model for optimal harvesting with functional response incorporating prey refuge

Maiti, M., see De, A.

Maity, K., see De, A.

Mannar Jawahar, P., see Kamalanand, K.

McCarthy, M. L. \& Whiteman, H. H., A model of inter-cohort cannibalism and paedomorphosis in Arizona Tiger Salamanders, Ambystoma tigrinum nebulosum

Modnak, C., see Posny, D.

Mohammadi, F., Fallahchai, M. M. \& Hashemi, S. A., Application of probability distribution in order to fit the diameter and height of oak species in two natural and man-made stands in Hyrcanian forests

Mohyud-Din, S. T., Ali, A. \& Bin-Mohsin, B., On biological population model of fractional order

Mohyud-Din, S. T., Waheed, A. \& Rashidi, M. M., A study of nonlinear age-
3 (2016) 1650048

1 (2016) 1650011

3 (2016) 1650046

5 (2016) 1650077

3 (2016) 1650044

5 (2016) 1650072

1 (2016) 1650014

6 (2016) 1650088

6 (2016) 1650088

2 (2016) 1650024

2 (2016) 1650030

1 (2016) 1650001

5 (2016) 1650070 structured popula-

tion models

6 (2016) 1650091

Mohyud-Din, S. T., see Iqbal, M. A.

5 (2016) 1650071

Mohyud-Din, S. T., see Ul Hassan, Q. M.

Mojaver, A. \& Kheiri, H., Dynamical analysis of a class of hepatitis $C$ virus infection models with application of optimal control

Mondal, B., see Guin, L. N.

Moneim, I. A., Modeling and simulation of the spread of H1N1 flu with periodic vaccination

Mukherjee, D., see Ghosh, P.

Munawar, S., see Saleem, N.

Nieto, J. J., see Andrade, H.

2 (2016) 1650026

3 (2016) 1650038

6 (2016) 1650085

1 (2016) 1650003

5 (2016) 1650073

2 (2016) 1650027

4 (2016) 1650053

Pei, Y., Chen, M., Liang, X., Xia, Z., Lv, Y. \& Li, C., Optimal control problem in an epidemic disease SIS model with stages and delays

Perasso, A., see Bahi, J. M.

5 (2016) 1650072

5 (2016) 1650076

Petukhov, A. Y. \&

Polevaya, S. A.,

Modeling of information images dynamics through the communicative field method

4 (2016) 1650057

Petukhov, A. Y.,

Polevaya, S. A. \&

Yakhno, V. G., The

theory of information images: Modeling based on diffusion equations

Polevaya, S. A., see Petukhov, A. Y.

Polevaya, S. A., see Petukhov, A. Y.

Posny, D., Modnak, C. \& Wang, J., A multigroup model for cholera dynamics and control
1 (2016) 1650001 
Qureshi, M. N., see Khan, A. Q.

Raja Sekhar, G. P., see Dey, B.

Ramathilagam, S., see Kannan, S. R.

Ramu, A., see Satpathi, D. K.

Rashidi, M. M., see Mohyud-Din, S. T.

Rasouli, S. H., An ecological model with the $p$-Laplacian and diffusion

Rathod, V. P., see Tanveer, S.

Ratnam, K. V., see Satpathi, D. K.

Ravikumar, A., see Kannan, S. R.

Rezvan, A., see Aghdam, $\mathrm{R}$.

Roman, M. \& Selişteanu, D., Modeling of microbial growth bioprocesses: Equilibria and stability analysis

Roy, P. K., Chatterjee, A. N. \& Li, X.-Z., The effect of vaccination to dendritic cell and immune cell interaction in $\mathrm{HIV}$ disease progression

Saleem, N. \& Munawar, S., A mathematical analysis of MHD blood flow of Eyring-Powell fluid through a constricted artery

Sankar, D. S., Perturbation analysis for pulsatile flow of Carreau fluid through tapered stenotic arteries

Santra, P., see

Mahapatra, G. S.

Sarwar, S., Zahid, M. A. \& Iqbal, S., Mathematical study of fractional-order biological population model using optimal
2 (2016) 1650021

6 (2016) 1650095

2 (2016) 1650018

5 (2016) 1650074

6 (2016) 1650091

1 (2016) 1650008

2 (2016) 1650025

5 (2016) 1650074

2 (2016) 1650018

3 (2016) 1650040

5 (2016) 1650067

1 (2016) 1650005

2 (2016) 1650027

4 (2016) 1650063

1 (2016) 1650014 homotopy asymptotic method

6 (2016) 1650081

Satpathi, D. K., Ratnam, K. V. \& Ramu, A., Model for mucus transport in the airways due to air motion: Effect of slipperiness

5 (2016) 1650074

Selişteanu, D., see

Roman, M.

Sharma, A. K., Sharma, A. \& Agnihotri, K., Bifurcation behaviors analysis of a plankton model with multiple delays

6 (2016) 1650086

Sharma, A., see Sharma, A. K.

6 (2016) 1650086

Sharma, M. D., see Kamboj, D.

She, Z., see Li, H.

Shokry, M., see

El-Sharkasy, M. M.

Song, G., see Zhang, M.

Song, H., Jiang, W. \&

Liu, S., Global

dynamics of two

heterogeneous SIR

models with nonlinear incidence and delays

Sreenadh, S., see Vajravelu, K.

Su, Z., see Wang, Z.

Sucharitha, G., see Vajravelu, K.

Tan, J. \& Li, C., Global synchronization of discrete-time coupled neural networks with Markovian switching and impulses

3 (2016) 1650041

Tanveer, S. \& Rathod, V. P., Gravity flow of pulsatile blood through a porous medium under periodic body acceleration and magnetic field in an inclined tube

5 (2016) 1650065

4 (2016) 1650050

4 (2016) 1650059

4 (2016) 1650062

3 (2016) 1650046

2 (2016) 1650023

2 (2016) 1650019

2 (2016) 1650023

Thakur, N. K., Tiwari, S. K. \& Upadhyay, R. K., Harmful algal blooms in fresh and 
marine water systems:

The role of toxin

producing phyto-

plankton

Tian, B., Zhong, S. \&

Liu, Z., Extinction and

persistence of a

nonautonomous

stochastic food-chain

system with impulsive

perturbations

Tian, X., see Wang, J.

Tiwari, S. K., see

Thakur, N. K.

Torres, A., see Andrade, $\mathrm{H}$.

Ul Hassan, Q. M. \& Mohyud-Din, S. T., Investigating biological population model using exp-function method

Upadhyay, R. K., see

Thakur, N. K.

Vajravelu, K., Sreenadh, S., Lakshminarayana, P. \& Sucharitha, G., The effect of heat transfer on the nonlinear peristaltic transport of a Jeffrey fluid through a finite vertical porous channel

Veer, K., Spectral and mathematical evaluation of electromyography signals for clinical use

Waheed, A., see

Mohyud-Din, S. T.

Wang, D., see Xia, Z.

Wang, F., see Li, J.-H.

Wang, F., see Zhu, H.

Wang, H., see Zhu, H.

Wang, H.-T., see He, Z.-R.

Wang, J., Tian, X. \& Wang, X., Stability analysis for delayed viral infection model with multitarget cells and general incidence rate

Wang, J., see Posny, D.

Wang, K., see Liu, M.
1 (2016) 1650007

3 (2016) 1650043

5 (2016) 1650077

1 (2016) 1650007

3 (2016) 1650043

4 (2016) 1650053

2 (2016) 1650026

3 (2016) 1650043

2 (2016) 1650023

6 (2016) 1650094

6 (2016) 1650091

5 (2016) 1650078

4 (2016) 1650064

5 (2016) 1650079

5 (2016) 1650079

6 (2016) 1650093

1 (2016) 1650001

1 (2016) 1650011
Wang, L. \& Xu, R., Global stability of an SEIR epidemic model with vaccination

6 (2016) 1650082

Wang, Q., Bifurcation analysis in a predator-prey model for the effect of delay in prey

4 (2016) 1650061

Wang, X., see Wang, J.

Wang, X., see Wang, Z.

Wang, Z., Ji, Z., Su, Z.,

1 (2016) 1650007

2 (2016) 1650019

Wang, X. \& Zhao, K.,

Solving the maximal

matching problem with

DNA molecules in

Adleman-Lipton

model

2 (2016) 1650019

Wei, F. \& Fu, Q., Globally asymptotic stability of a predator-prey model with stage structure incorporating prey refuge

4 (2016) 1650058

Whiteman, H. H., see McCarthy, M. L.

Wu, Z., see Zhou, T.

Xia, Z. \& Wang, D., Pseudo-almost periodic solution for impulsive hematopoiesis model with infinite delays and linear harvesting term

Xia, Z., see Pei, Y.

Xiang, M., see Zhou, T.

Xie, Q.-J., see He, Z.-R.

$\mathrm{Xu}, \mathrm{R}$., see Wang, L.

Yakhno, V. G., see Petukhov, A. Y.

Yang, H., Stability and Hopf bifurcation for a logistic SIR model with a stage - Structure

2 (2016) 1650030

3 (2016) 1650035

5 (2016) 1650078

5 (2016) 1650072

3 (2016) 1650035

6 (2016) 1650093

6 (2016) 1650082

6 (2016) 1650087

Yang, J., Li, X. \& Zhang, F., Global dynamics of a heroin epidemic model with age structure and nonlinear incidence

Yao, Z., Existence and exponential stability of almost periodic positive solution for
1 (2016) 1650013

3 (2016) 1650033 
host-macroparasite

difference model

Yao, Z., Almost periodic solution of Nicholson's blowflies difference equation with linear harvesting term

Yasmin, H., see Hayat, $\mathrm{T}$.

2 (2016) 1650028

4 (2016) 1650052

1 (2016) 1650012

Yu, M. \& Liu, J., Subspace identification for a stochastic model of plague

Yuan, S., see Ji, X.

Yüzbaşı, Ş., A collocation method for numerical solutions of fractional-order logistic population model

Yüzbaşı, Ş., An exponential collocation method for the solutions of the HIV infection model of $\mathrm{CD} 4^{+} \mathrm{T}$ cells

3 (2016) 1650036

Zahid, M. A., see Sarwar, $\mathrm{S}$.

6 (2016) 1650081

3 (2016) 1650033

1 (2016) 1650015

Zhang, L., see Li, Y.

Zhang, M. \& Song, G., The effect of diffusion loss on the timevarying giant Panda population

Zhang, M. \& Zhang, Y., Fractal analysis and control of the competition model

5 (2016) 1650069

6 (2016) 1650083

2 (2016) 1650031

4 (2016) 1650062
Zhang, Q., see Zhang, Y.

3 (2016) 1650034

Zhang, X., see Zhou, T.

3 (2016) 1650035

Zhang, Y., Zhang, Q. \& Zhao, L., Optimal harvest of an interval model of carbon sink fisheries with multitrophic levels

3 (2016) 1650034

5 (2016) 1650084

Zhang, Y., see Jiao, J.

Zhang, Y., see Zhang, M.

3 (2016) 1650045

Zhao, K., see Wang, Z.

2 (2016) 1650019

Zhao, L., see Zhang, Y.

Zhao, Y. \& Jiang, D.,

The asymptotic

behavior and ergodicity

of stochastically

perturbed SVIR

epidemic model

3 (2016) 1650042

Zhong, S., see Tian, B.

Zhou, T., Zhang, X.,

Xiang, M. \& Wu, Z.,

Permanence and

almost periodic

solution of a

predator-prey discrete system with Holling IV functional response

3 (2016) 1650035

Zhu, H., Ding, Q., Wang, F. \& Wang, H., Dynamics on tumor immunotherapy model with periodic impulsive infusion

5 (2016) 1650079

Zhu, H., see Ji, X.

6 (2016) 1650083

Zou, R.-B., see Li, J.-H.
4 (2016) 1650064 